\title{
External Beam Radiation in Differentiated Thyroid Carcinoma
}

\author{
Salem Billan, M.D. ${ }^{1 *}$, and Tomer Charas, M.D. ${ }^{2}$ \\ ${ }^{\prime}$ Department of Oncology, Princess Margaret Hospital, Toronto, Canada; and ${ }^{2}$ Division of Oncology, \\ Rambam Health Care Campus, Haifa, Israel
}

\begin{abstract}
The treatment of differentiated thyroid carcinoma (DTC) is surgery followed in some cases by adjuvant treatment, mostly with radioactive iodine (RAI). External beam radiotherapy (EBRT) is less common and not a well-established treatment modality in DTC. The risk of recurrence depends on three major prognostic factors: extra-thyroid extension, patient's age, and tumor with reduced iodine uptake. Increased risk for recurrence is a major factor in the decision whether to treat the patient with EBRT. Data about the use of EBRT in DTC are limited to small retrospective studies. Most series have demonstrated an increase in locoregional control. The risk/benefit from giving EBRT requires careful patient selection. Different scoring systems have been proposed by different investigators and centers. The authors encourage clinicians treating DTC to become familiarized with those scoring systems and to use them in the management of different cases. The irradiated volume should include areas of risk for microscopic disease. Determining those areas in each case can be difficult and requires detailed knowledge of the surgery and pathological results, and also understanding of the disease-spreading pattern. Treatment with EBRT in DTC can be beneficial, and data support the use of EBRT in high-risk patients. Randomized controlled trials are needed for better confirmation of the role of EBRT.
\end{abstract}

KEY WORDS: Carcinoma, external beam, radiotherapy, thyroid

\begin{abstract}
Abbreviations: ATC, anaplastic thyroid carcinoma; DTC, differentiated thyroid carcinoma; EBRT, external beam radiotherapy; FTC, follicular thyroid carcinoma; IMRT, intensity-modulated radiation therapy; PTC, papillary thyroid carcinoma; RAI, radioactive iodine.
\end{abstract}

Citation: Billan S, Charas T. External Beam Radiation in Differentiated Thyroid Carcinoma. Rambam Maimonides Med J 2016;7 (1):e0oo8. doi:10.5041/RMMJ.10235 Review

Copyright: (C) 2016 Billan and Charas. This is an open-access article. All its content, except where otherwise noted, is distributed under the terms of the Creative Commons Attribution License (http://creativecommons.org/licenses/by/3.0), which permits unrestricted use, distribution, and reproduction in any medium, provided the original work is properly cited.

Conflict of interest: No potential conflict of interest relevant to this article was reported.

* To whom correspondence should be addressed. E-mail: s_billan@rambam.health.gov.il 


\section{INTRODUCTION}

Thyroid cancer is one of the most common malignancies throughout the world, with incidence and prevalence on the rise in recent years in Israel and worldwide. ${ }^{1,2}$ Most thyroid cancers originate from glandular epithelial cells and are divided by their histological malignancy source into papillary (PTC), follicular (FTC), and anaplastic (ATC) thyroid carcinomas, with prevalences of $80 \%, 15 \%$, and $\sim 2 \%$, respectively. 3

The treatment of differentiated thyroid carcinoma (DTC) is primary surgery (hemithyroidectomy or total thyroidectomy, with or without neck dissection), followed by adjuvant treatment given depending on the stage and risk profile of the tumor, most commonly radioactive iodine (RAI) in medium- and high-risk patients. 4,5

Differentiated thyroid carcinoma is a radiosensitive cancer, proven by the effectivity of using radiation treatment in the form of RAI. Another form of radiation treatment, external beam radiotherapy (EBRT), a term used when radiation originates from an external source, is one of the pillars of oncological treatments for cancers; however, it is less commonly used in the treatment of DTC.

We present the relevant literature and indications for EBRT in the treatment of DTC. We discuss the prognostic factors for loco-regional relapse and the role of EBRT in reducing the risk of locoregional recurrence in the presence of such prognostic factors.

\section{PROGNOSTIC FACTOR FOR LOCAL RECURRENCE}

Cancer recurrence occurs in $10 \%-15 \%$ of patients with DTC and is most frequently confined to the neck. ${ }^{6}$ The risk of recurrence depends on three major prognostic factors: extra-thyroid extension, patient's age, and tumor with reduced iodine uptake. ${ }^{7-10}$

\section{Extra-thyroid Extension}

Extra-thyroid extension is a known risk factor for recurrence and death from DTC. In approximately $10 \%$ of DTC cases, the primary tumor extends through the thyroid gland capsule, leading to a poor prognosis, with death rates in the range of $5 \%-$ $35 \% .{ }^{11}$ In a report by Loh et al., patients with extrathyroid extension (stage $\mathrm{T} 4$ ) had more than a 3 -fold risk of recurrence and death compared with those with large but thyroid-confined (stage T3) tumors. ${ }^{12}$ The effectiveness of adjuvant RAI treatment is reduced in the presence of extra-thyroid extension and extra-thyroidal disease.

\section{Patient's Age}

The risks of both recurrence and death increase also with increased patient's age. This can partially be explained by the fact that tumors in older patients are less differentiated and are less likely to concentrate RAI. ${ }^{13,14}$

\section{Reduced Iodine Uptake}

Reduced iodine uptake is also associated with a worse prognosis and increased risk of recurrence. Hürthle cell carcinomas, a known variant of PTC, have reduced RAI uptake compared to other PTC variants or follicular carcinomas. In a series of 101 patients with distant metastases, RAI uptake by pulmonary metastases was demonstrated in $64 \%$ of follicular carcinomas and $60 \%$ of papillary carcinomas, compared to only $36 \%$ of Hürthle cell carcinomas. ${ }^{15}$

\section{EBRT THERAPY}

The use of external beam radiotherapy in the majority of solid cancer types increases local control, decreases the risk of recurrence, and even improves survival. ${ }^{16}$ The role of EBRT in DTC remains controversial due to the lack of randomized controlled trials and the reliance on single institution experiences and retrospective reviews, which include data that are usually biased for inconsistency in pathology assessments, surgical technique, and radiation therapy techniques, doses, and target definitions. We used the PubMed database for our primary search, which included EBRT and differentiated or papillary carcinoma search words. We employed the reference lists of the full-text articles that we retrieved electronically. Studies that reviewed the topic in terms of EBRT outcomes were included. Considering the level of evidence of EBRT efficacy in DTC and potential EBRT morbidity (including mucositis, pharyngitis, xerostomia, thick saliva, skin fibrosis, tracheal stenosis, and esophageal stricture), the decision of treatment for each case is challenging, which has brought many institutions and leading physicians to develop a "case-by-case" approach.

Treatment with EBRT has been known to control unresectable and gross residual thyroid cancer at least since the 1960 s. Chow et al. ${ }^{17}$ reported a large 
retrospective cohort study and found a statistically significant improvement in loco-regional control in the subgroup of patients with macroscopic nonpalpable residual disease treated with EBRT compared to those not irradiated (10-year loco-regional control rate $79.2 \%$ with EBRT versus 39\% without EBRT, $P<0.001)$. This study revealed a statistically significant increase in 10-year cause-specific survival (CSS) (74.1\% with EBRT, $49.7 \%$ without EBRT, $P=0.01)$ after treatment with EBRT. Similar longterm control of gross disease has been shown by others. $^{8}$

Treatment with EBRT can also increase local control and local failure-free rates in microscopic disease. Several reports of retrospective reviews, in which local control was improved after EBRT in patients with high-risk microscopic disease compared with patients who did not receive EBRT, are listed in Table 1.

The most convincing report is from a study by Farahati et al. ${ }^{21}$ that reviewed 125 DTC patients with a high risk of local recurrence due to extra-thyroid extension and patient age over 40 years. All patients received the same treatment, including surgery followed by RAI therapy and thyroid-stimulating hormone suppression. The addition of EBRT improved the 5-year loco-regional control from $60 \%$ to 90\%; EBRT was a predictive factor for improvement in time to distant failure $(P<0.0003)$.
A study by Brierley et al. $3^{\circ}$ demonstrated improvement in loco-regional control and statistically significant better outcomes in patients over the age of 60 years receiving EBRT for thyroid carcinoma with microscopic residual disease, $\mathrm{T} 4$ disease, and no metastases. The 10-year loco-regional relapse-free rate was $86.4 \%$ with EBRT versus $65.7 \%$ without EBRT $(P<0.01)$.

Other studies have reported significantly improved loco-regional control in similar subgroups with advanced local disease and/or postoperative residual disease. ${ }^{21,22}$ In contrast, two large retrospective reviews failed to show any difference in loco-regional control in patients who had received EBRT compared with those who had not.22,31

A recently published systematic review by Fussey et al.32 confirms the improvement in loco-regional control with EBRT in the older patient population with high-risk features.

\section{PATIENT SELECTION FOR EBRT}

The potential benefit from the addition of EBRT needs to be balanced with the generally excellent outcomes with surgery and RAI, as well as the expected side effects of EBRT. Another key issue is whether improvement in local control only is sufficient to indicate irradiation, given the fact that local relapses may be salvaged with surgery and RAI.

Table 1. Ten-year Loco-regional Control Rates in the High-risk Differentiated Thyroid Carcinoma Patients without Gross Residual Disease.

\begin{tabular}{|l|c|c|c|}
\hline \multicolumn{1}{|c|}{ First Author } & Year of Publication & Surgery/RAI/EBRT (\%) & Surgery/RAl (\%) \\
\hline Tubiana et al. ${ }^{18}$ & 1985 & 86 & 79 \\
Simpson et al. $^{19}$ & 1990 & 86 & 82 \\
Philips et al. $^{20}$ & 1993 & 97 & 79 \\
Farahati et al. $^{21}$ & 1996 & 90 & 50 \\
Tsang et al. $^{22 *}$ & 1998 & 93 & 78 \\
Ford et al. $^{23}$ & 2003 & 82 & 37 \\
Kim et al. ${ }^{24}$ & 2003 & 95 & 63.5 \\
Brierley et al. $^{25}$ & 2005 & 86 & 65 \\
Keum et al. ${ }^{26}$ & 2006 & 72 & 11 \\
Meadows et al. ${ }^{27}$ & 2006 & 89 & N/A \\
Terezakis et al..$^{28}$ & 2009 & 75 & N/A \\
Schwartz et al. ${ }^{29}$ & 2009 & 79 & N/A \\
\hline
\end{tabular}

* Papillary only; ${ }^{\dagger}$ Patients $>60 \mathrm{y}$. 
To better define the subgroup of patients who would benefit the most from EBRT, different scoring systems were developed. ${ }^{33,34}$ Detailed in Table 2 is the scoring system proposed by a French group that is currently being tested in a prospective study. This scoring system takes into account classical prognostic factors and histology, gender, and recurrent disease. In cases with scores above 4, EBRT should be discussed, and, in scores above 6, EBRT is recommended. 35

Patient selection for EBRT can be challenging, and the authors' opinion is that cases should be discussed in multidisciplinary tumor boards that include surgeons, endocrinologists, specialists from the radiation and medical oncology fields, diagnostic specialists (radiology and nuclear medicine), and pathologists. In our hospital, we recommend EBRT for patients older than 60 years of age with nonradioactive avid residual macroscopic disease that was considered not operable. Patients older than 60 years of age with microscopic residual disease are likely to develop an early recurrence that will most likely be non-operable and unlikely to respond to RAI.

\section{RADIATION VOLUME, DOSE, AND TECHNIQUE}

There is no clear recommendation regarding radiation volume. At Rambam Health Care Campus, the irradiated volume depends on the disease spread pattern. In cases with locally advanced disease with extra-thyroid extension without lymph node involvement, the volume includes the thyroid bed and only the immediate adjacent lymph node areas (commonly levels 6 and 4). In cases with multiple lymph node involvement, the irradiated volume would include most of the lymph node levels, including levels 2, 3, 4, 5 bilaterally, level 6 , and upper mediastinum, in addition to the tumor bed. This volume is adjusted as required depending on the preoperative imaging, the report of the surgeon at the time of resection, and the pathology report.

The EBRT dose is typically in the range of 60-66 Gy to areas of microscopic disease. When resection is incomplete, the dose to regions of known gross disease is increased to $70 \mathrm{~Gy}$. Often, the energy used is $6 \mathrm{MV}$; however, when 3-dimensional planning is done, coverage of deeper structures can be achieved using $18 \mathrm{MV}$ beam energy.

Achieving loco-regional control is paramount in patients treated with EBRT. Therefore, it is important to deliver a high dose of radiation, without causing injury to the surrounding normal tissues. This is can be achieved relatively easily using modern radiation techniques, such as intensitymodulated radiation therapy (IMRT). In a comparison study between IMRT and 3-dimensional conformal radiotherapy treatment plans, the Royal Marsden Hospital reported that the IMRT plan resulted in improved coverage of the planning volume and lower spinal cord dose. 36

\section{CONCLUSIONS}

Treatment with EBRT should be reserved for patients who are at high risk of loco-regional recur-

Table 2. Proposed Scoring System for Differentiated Thyroid Carcinoma. ${ }^{23}$

\begin{tabular}{|c|c|c|c|c|}
\hline & 0 Point & 1 Point & 2 Points & 4 Points \\
\hline Age (years) & $<45$ & $45-60$ & $>60$ & \\
\hline Gender & Female & Male & & \\
\hline Resectability & Resectable & & & Unresectable \\
\hline Extensive extra-capsular nodal spread & No & & Yes & \\
\hline Extra-thyroidal disease & & T3 & T4 & \\
\hline R0-R1-R2 & RO & & $\mathrm{R} 1$ & $\mathrm{R} 2$ \\
\hline $\begin{array}{l}\text { Histological variants (tall-cell, Hürthle cell, } \\
\text { columnar, diffuse sclerosing, solid variant) }\end{array}$ & No & Yes & & \\
\hline $\begin{array}{l}\text { Recurrent disease (risk of recurrent nerve } \\
\text { damage, etc.) }\end{array}$ & No & & Yes & \\
\hline Tumors with radioiodine fixation & Yes & & & No \\
\hline
\end{tabular}


rence, and clinicians are urged to consider the potential benefits and possible toxicity. To date, there is sufficient evidence to support the use of EBRT in DTC. However, randomized control trials are warranted.

\section{REFERENCES}

1. Altekruse et al. SEER Cancer Statistics Review, 19752007. National Cancer Institute. Based on November 2009 SEER data submission, posted to the SEER web site, 2010. Available at: http://1.usa.gov/1RtrLoA. Accessed January 2016.

2. Ministry of Health Israel. Thyroid cancer. Available at: http://bit.ly/1OVBIDw. Accessed January 2016.

3. SEER Cancer Statistics Review, 1975-2007. National Cancer Institute. Based on November 2009 SEER data submission, posted to the SEER web site, 2010. Available at: http://1.usa.gov/237LpmL. Accessed January 2016.

4. Sherman SI. Thyroid carcinoma. Lancet 2003;361: 501-11. Full Text

5. Pacini F, Schlumberger M, Dralle H, et al.; European Thyroid Cancer Taskforce. European consensus for the management of patients with differentiated thyroid carcinoma of the follicular epithelium. Eur J Endocrinol 2006;154:787-803. Full Text

6. Schlumberger M, Sherman SI. Approach to the patient with advanced differentiated thyroid cancer. Eur J Endocrinol 2012;166:5-11. Full Text

7. Lee N, Tuttle M. The role of external beam radiotherapy in the treatment of papillary thyroid cancer. Endocr Relat Cancer 2006;13:971-7. Full Text

8. Brierley JD, Tsang RW. External beam radiation therapy for thyroid cancer. Endocrinol Metab Clin North Am 2008;37:497-509. Full Text

9. Strasser JF, Raben A, Koprowski C. The role of radiation therapy in the management of thyroid cancer. Surg Oncol Clin N Am 2008;17:219-32. Full Text

10. Mazzarotto R, Cesaro MG, Lora O, Rubello D, Casara D, Sotti G. The role of external beam radiotherapy in the management of differentiated thyroid cancer. Biomed Pharmacother 2000;54:345-9. Full Text

11. Mazzaferri EL, Jhiang SM. Long-term impact of initial surgical and medical therapy on papillary and follicular thyroid cancer. Am J Med 1994;97:418-28. Full Text

12. Loh KC Greenspan FS, Gee L, Miller TR, Yeo PP. Pathological tumor-node-metastasis (pTNM) staging for papillary, and follicular thyroid carcinomas: a retrospective analysis of 700 patients. J Clin Endocrinol Metab 1997;82:3553-62. Full Text

13. Coburn MC, Wanebo HJ. Age correlates with increased frequency of high risk factors in elderly patients with thyroid cancer. Am J Surg 1995;170: 471-5. Full Text

14. Bacourt F, Asselain B, Savoie JC, et al. Multifactorial study of prognostic factors in differentiated thyroid carcinoma and a reevaluation of the importance of age. Br J Surg 1986;73:274-7. Full Text

15. Samaan NA, Schultz PN, Haynie TP, Ordonez NG. Pulmonary metastasis of differentiated thyroid carcinoma: treatment results in 101 patients. $\mathrm{J}$ Clin Endocrinol Metab 1985;60:376-80. Full Text

16. Halperin EC, Brady LW, Perez CA, Wazer DE. Perez and Brady's Principles and Practice of Radiation Oncology. 6th ed. Philadelphia, PA: Lippincot Williams and Wilkins; 2013:6E:16, section I.

17. Chow SM, Law SC, Mendenhall WM, et al. Papillary thyroid carcinoma: prognostic factors and the role of radioiodine and external radiotherapy. Int $\mathrm{J}$ Radiat Oncol Biol Phys 2002;52:784-95. Full Text

18. Tubiana M, Haddad E, Schlumberger M, Hill C, Rougier P, Sarrazin D. External radiotherapy in thyroid cancers. Cancer 1985;55:2062-71. Full Text

19. Simpson WJ. Radioiodine and radiotherapy in the management of thyroid cancers. Otolaryngol Clin North Am 1990;23:509-21.

20. Phlips P, Hanzen C, Andry G, Van Houtte P, Früuling J. Postoperative irradiation for thyroid cancer. Eur J Surg Oncol 1993;19:399-404.

21. Farahati J, Reiners C, Stuschke M, et al. Differentiated thyroid cancer. Impact of adjuvant external radiotherapy in patients with perithyroidal tumor infiltration (stage pT4). Cancer 1996;77:172-80. Full Text

22. Tsang RW, Brierley JD, Simpson WJ, Panzarella T, Gospodarowicz MK, Sutcliffe SB. The effects of surgery, radioiodine and external radiation therapy on the clinical outcome of patients with differentiated thyroid cancer. Cancer 1998;82:375-88. Full Text

23. Ford D, Giridharan S, McConkey C, et al. External beam in the management of differentiated thyroid cancer. Clin Oncol (R Coll Radiol) 2003;15:337-41. Full Text

24. Kim TH, Yang DS, Jung KY, Kim CY, Choi MS. Value of external irradiation for locally advanced papillary thyroid cancer. Int $J$ Radiat Oncol Biol Phys 2003;55: 1006-12. Full Text

25. Brierley J, Tsang R, Panzarella T, Bana N. Prognostic factors and the effect of treatment with radioactive 
iodine and external beam radiation on patients with differentiated thyroid cancer seen at a single institution over 40 years. Clin Endocrinol (Oxf) 2005;63: 418-27. Full Text

26. Keum KC, Suh YG, Koom WS, et al. The role of postoperative external beam radiotherapy in the management of patients with papillary thyroid cancer invading the trachea. Int J Radiat Oncol Biol Phys 2006;65:474-80. Full Text

27. Meadows KM, Amdur RJ, Morris CG, Villaret DB, Mazzaferri EL, Mendenhall WM. External beam radiotherapy for differentiated thyroid cancer. Am J Otolaryngol 2006;27:24-8. Full Text

28. Terezakis SA, Lee KS, Ghossein RA, et al. Role of external beam radiotherapy in patients with advanced or recurrent nonanaplastic thyroid cancer: Memorial Sloan-Kettering cancer center experience. Int $\mathrm{J}$ Radiat Oncol Biol Phys 2009;73:795-801. Full Text

29. Schwartz DL, Lobo MJ, Ang KK, et al. Postoperative external beam radiotherapy for differentiated thyroid cancer: Outcomes and morbidity with conformal treatment. Int $\mathrm{J}$ Radiat Oncol Biol Phys 2009;74:1083-91. Full Text

30. Brierley J, Tsang R, Simpson WJ, Gospodarowicz M, Sutcliffe S, Panzarella T. Medullary thyroid cancer: analyses of survival and prognostic factors and the role of radiation therapy in local control. Thyroid 1996;6:305-10. Full Text
31. Lin JD, Tsang NM, Huang MJ, Weng HF. Results of external beam radiotherapy in patients with well differentiated thyroid carcinoma. Jpn J Clin Oncol 1997;27:244-7. Full Text

32. Fussey JM, Crunkhorn R, Tedla M, Weickert MO, Mehanna H. External beam radiotherapy in differentiated thyroid carcinoma: a systematic review. Head Neck. 2015 Sep 3. [Epub ahead of print]. Full Text

33. Buffet C, Golmard JL, Hoang C, et al. Scoring system for predicting recurrences in patients with papillary thyroid microcarcinoma. Eur J Endocrinol 2012;167: 267-75. Full Text

34. Welsch M, Abeln M, Zaplatnikov K, et al. Multiparameter scoring system for the prognosis of differentiated thyroid cancer. Nuklearmedizin 2007;46: 257-62. Full Text

35. Sun XS, Sun SR, Guevara N, et al. Indications of external beam radiation therapy in non-anaplastic thyroid cancer and impact of innovative radiation techniques. Crit Rev Oncol Hematol 2013;86:52-68. Full Text

36. Nutting CM, Convery DJ, Cosgrove VP, et al. Improvements in target coverage and reduced spinal cord irradiation using intensity-modulated radiotherapy (IMRT) in patients with carcinoma of the thyroid gland. Radiother Oncol 2001;60:173-80. Full Text 